\title{
Repetitive brief ischemia accelerates tibial shaft fracture healing: a 5-years prospective preliminary clinical trial (PCT)
}

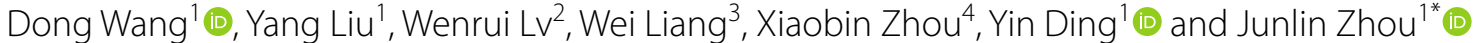

\begin{abstract}
Background: This study was to evaluate the effects of repetitive brief ischemia (RBI) on bone healing in patients with tibial shaft fractures.

Methods: In this prospective clinical trial, patients with tibia shaft fractures were enrolled between January 2016 and January 2021. The intermittent pneumatic compression (IPC) device was used to make RBI on the affected limb after surgical operation $24 \mathrm{~h}$. The inflation pressure was the systolic pressure of patients $+50 \mathrm{mmHg}$. Patients were received $30 \mathrm{~s}$ inflation/30 s deflation 30 times twice a day for 4 weeks. The primary outcome was bone healing time and the secondary outcomes were the rates of delayed union and nonunion, the rates of venous thrombosis of lower limbs, Johner-Wruhs scores, Lysholm knee score, VAS scores, postoperative complications, serum BMP-2, osteocalcin (OC) and bone specific alkaline phosphatase (BS-ALP).

Results: A total of 32 patients were enrolled finally and all were completed with a 12 months follow-up. All the fractures were healed and the bone healing time was 3(1) months in RBI group. However, the bone healing time of control group was $4(1)$ and there was statistical difference between the two groups $(p<0.01)$. No patient with fracture delayed union, nonunion and venous thrombosis of lower limbs in RBI group. 2 patients were delayed union in the control group. In RBI group, the Lysholm knee score was 83(6) at 6 months and 100(8) at 12 months. In the control group, the score was 78(4) and 90.5(17), there was statistical difference between the two groups $(p<0.01, p=0.014$, respectively). VAS scores were postoperative 2 weeks $6(1)$ in RBI group and 7(0.5) in the control group, there was statistical difference between the two groups $(p=0.016)$. There were 2 patients with intramuscular venous thrombosis of lower extremity in control group. Besides, RBI treatment increased the serum BMP-2, OC and BS-ALP at postoperative 2 weeks and 1 month.
\end{abstract}

Conclusions: RBI is a new method to accelerate bone healing in tibia shaft fracture patients and is a simple and noninvasive method.

Trial registration: Chinese clinical trial registry, ChiCTR-INR-17014208. Registered 28 December 2017-Retrospectively registered.

Keywords: Repetitive brief ischemia, Tibia shaft fractures, Bone healing, Intermedullary nail, Prospective clinical trials, Serum vytokines

\footnotetext{
*Correspondence: junlinzhou_article@outlook.com

1 Department of Orthopedics, Beijing Chaoyang Hospital, Capital

Medical University, 8 Gongren Tiyuchang Nanlu, Chaoyang District, Beijing 100020, China

Full list of author information is available at the end of the article
}

\section{Introduction}

Fracture is the most common trauma in orthopaedics and causes more than 150,000 patients hospitalisations in Australia each year [1]. Although there are many ways to original author(s) and the source, provide a link to the Creative Commons licence, and indicate if changes were made. The images or other third party material in this article are included in the article's Creative Commons licence, unless indicated otherwise in a credit line to the material. If material is not included in the article's Creative Commons licence and your intended use is not permitted by statutory regulation or exceeds the permitted use, you will need to obtain permission directly from the copyright holder. To view a copy of this licence, visit http://creativecommons.org/licenses/by/4.0/. The Creative Commons Public Domain Dedication waiver (http://creativeco mmons.org/publicdomain/zero/1.0/) applies to the data made available in this article, unless otherwise stated in a credit line to the data. 
promote bone healing and some of them have been used in clinic, the rate of delayed union or nonunion has not decreased significantly $[2,3]$. The rate of bone nonunion is about $5-10 \%$ and tibia fracture nonunion or delayed union is $25 \%$ [3], besides, the direct costs for healthcare and loss of productivity in the first 6 months post-injury are about $\$ 23,000$ for each limb fracture. Once nonunion occurs, most of patients will undergo a revision surgery, which will cause a secondary injury of the patients. Even if the fracture is healed after revision treatment, it is difficult to recover the function of the affected limb. Therefore, as the nonunion rate of tibial fracture, we are looking for a new method to accelerate bone healing and reduce the nonunion rate.

Ischemia preconditioning can improve skin flap survival which gives us a new idea. In 2016, we explored the effects of affected limb repetitive brief ischemia (RBI) on bone healing in a rat tibia fracture model and found that RBI treatment can promote fracture healing and stimulate the secretion of IGF-2 [4]. In 2019, we further discussed that whether health limb RBI can accelerate fracture healing and raised that RBI on the affected side or the healthy side limb could promote bone healing and boosted the synthesis of BMP-2, VEGF, TGF- $\beta$, and ALP in the fracture region [5].

At present, there is no clinical study on the effect of RBI on fracture healing. This purpose of this study was to analyze the effects of RBI on bone healing in patients with tibial shaft fractures and preliminarily discuss the mechanism.

\section{Methods}

\section{Trial design}

This study was a 5-years prospective clinical trial of RBI on tibial shaft fracture healing and registrated in Chinese clinical trial registry (registration number was ChiCTRINR-17014208, 28/12/2017). Primary outcome was the bone healing time, in addition, the secondary outcomes were the rates of delayed union and nonunion, the rates of venous thrombosis of lower limbs, Johner-Wruhs scores, Lysholm knee score, visual analogue scale (VAS) scores, postoperative complications, such as wound infection, fracture of internal fixation, loss of fracture reduction and vascular or nerve injury, and serum cytokines, such as bone morphogenetic protein-2 (BMP-2), osteocalcin (OC) and bone specific alkaline phosphatase (BS-ALP). The study was performed at Beijing Chao-Yang hospital affiliated to Capital Medical University and the third hospital of Shijiazhuang between January 2016 and January 2021. It was approved by the ethics committee of Beijing Chao-Yang Hospital Affiliated to Capital Medical University (2017-5-8-2) and the third hospital of Shijiazhuang (2021-018). We could not reach the sample size required for the registration of this clinical trial even if the study time was extended. Therefore, this study was converted from a randomized controlled trial to a small size prospective clinical trial.

\section{Sample size}

Stata 12.0 software was used to calculate the sample size. There is no relevant clinical study on the effects of RBI on fracture healing and only a few animal studies clarified that RBI accelerated bone healing. Therefore, the relevant pre-experiment was carried out and two patients were enrolled. The fracture healing time of RBI therapy group were 2.5, 3.0 months. Besides, the fracture healing time of tibia shaft fracture was $4.2 \pm 1.025$ months as described by Lu Y [6]. Alpha was set as 0.01 (two-sided) and power was set as 0.95 . A total of 26 patients were required. The ratio of RBI therapy group and control group was 1 .

\section{Participants}

The inclusion criteria for participants was as follows: patients aged from 18 to 65 years old; patients with fresh, closed AO/OTA type 42 tibial shaft fracture; patients treated with closed and interlocking intramedullary nail internal fixation (the same operation team); patients signed informed consent for clinical research.

The exclusion criteria for participants was as follows: patients with pathological fractures and open fractures; patients combined with other fractures; patients with vascular diseases, such as aneurysm, arterial embolism, thromboangitis obliterans, arteriosclerotic obliterans, polyarteritis and deep venous thrombosis; patients with metabolic and immune diseases, such as systemic lupus erythematosus, polymyositis and Sjogren's syndrome; patients treated with long-term glucocorticoid therapy; patients with partial skin lesions at the root of the affected thigh and not suitable for RBI treatment; patients not cooperated with the study, withdrawal and loss of visit; patients who did not meet the inclusion criteria.

Two clinical observers (YL and DW) with clinical research experience enrolled the patients strictly according to the inclusion criteria. The baseline information of participants were recorded, such as patient's name, gender, age, affected side, body mass index (BMI), the cause of bone fracture, closed or opened fracture, combination diseases (hypertension, diabetes mellitus, coronary heart disease and cerebral infarction), smoking or not, excessive drinking or not, the time of trauma to operation, fracture classification (AO/OTA).

\section{Interventions}

Participants received RBI treatment after surgical operation $24 \mathrm{~h}$. The intermittent pneumatic compression (IPC) 
device (Zosing, Henan, China) was used to make RBI. The IPC device was described in previous studies [7-9] (Fig. 1). Briefly, it contained two parts: the air-bag part and cuff part. The air bag part included air-bag, pressure gauge and valve. The cuff part included a connecting tube and an inflatable cuff. The inflatable cuff was placed at the thigh root of the affected limb and inflated by squeezing the air-bag. The pressure of cuff was the systolic pressure of patients $+50 \mathrm{mmHg}$. After inflation for $30 \mathrm{~s}$ (or terminated at any time if the patient's intolerance), the valve was opened and the gas in the cuff was discharged until the pressure to $0 \mathrm{mmHg}$. After deflation for $30 \mathrm{~s}$, the valve was closed and cuff was inflated again. The above inflation/deflation cycle was repeated for 30 times twice a day for 4 weeks by two experienced researchers (WRL and WL). The researchers guided and recorded the patients through video dialogue after the patients discharged from hospital.

The patients in the control group did not receive the RBI therapy.

\section{Outcomes}

Two experienced researchers (DW and XBZ) recorded the outcomes. The primary outcome was the bone healing time and bone fracture healing criteria were no pressure pain and longitudinal percussion pain in the fracture area, fuzzy fracture line on X-ray, 3/4 cortical connection and no pain after complete weight-bearing $[10,11]$. The secondary outcomes were the rates of delayed union and nonunion, the rates of venous thrombosis of lower limbs, Johner-Wruhs scores, Lysholm knee score, VAS scores, postoperative complications, and serum BMP-2, OC and BS-ALP $[12,13]$.

Delayed union criteria were that the fracture had not reached the healing criteria after 4 months $[14,15]$. There was less callus, slightly decalcified, obvious fracture line in the fracture area by X-ray, but no osteosclerosis was at the end of fracture $[14,15]$. The nonunion of fracture was that the fracture had not researched healing criteria after 8 months or the fracture end had been sclerotic $[14,15]$.
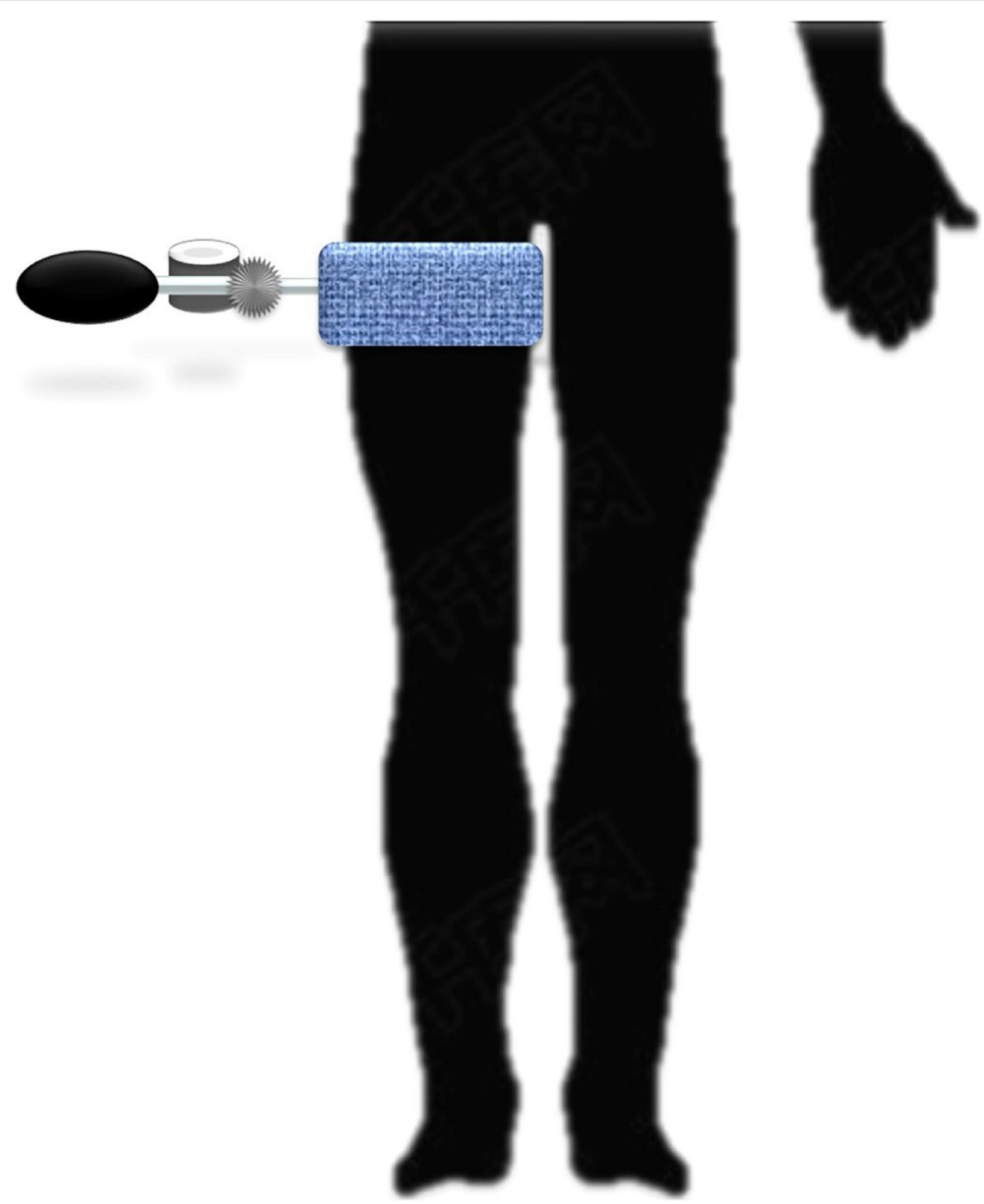

Fig. 1 The diagrammatic drawing of RBI using 
The postoperative outpatient follow-up timepoints were $1,2,3,4,6,8,12$ months. The end point of the trial was postoperative 12 months or patients diagnosed as nonunion. X-rays was used to evaluate the fracture healing at postoperative 1, 2, 3, 4, 6, 8, 12 months. Doppler ultrasound of lower extremity veins was used to diagnosed venous thrombosis of lower limbs at postoperative 1, 2, 3, 6, 12 months. Two researchers (DW and XBZ) were recorded the Johner-Wruhs scores, Lysholm knee score at postoperative 6,12 months, in addition, also recorded VAS scores at preoperative and postoperative 2 weeks, 1, 2, 3 months. Fasting blood was collected from the patients preoperative 1 day, postoperative 2 weeks, 1 , 2, 3 months. The serum BMP-2, OC and BS-ALP were detected by ELISA.

\section{Laboratory methods}

Human bone morphogenetic protein 2 ELISA kit (CSBE04507h, Cusabio, China), human osteocalcin ELISA kit (CSB-E05128h, Cusabio, China) and human bone alkaline phosphatase ELISA kit (CSB-E09033h, Cusabio, China) were used. $2 \mathrm{ml}$ blood collected from patients was centrifuged at $2500 \mathrm{rm} / \mathrm{r}, 25 \mathrm{~min}$. Then, BMP-2, OC and BS-ALP of supernatant were detected according to the instructions of ELISA kit.

\section{Statistical methods}

Stata 12.0 software was used to analyzed the data. Kolmogorov-Smirnova test was used to evaluate the normality of the measurement data. If the measurement data followed normal distribution, it was described as means \pm standard and compared by independent-sample $t$ test. If the measurement data obeyed the skewed distribution, it was represented by median (quartile range) and compared by Mann-Whitney U test. The enumeration data was represented by occurrence rate and compared by Chi-square test or Fischer's exact test. $P<0.05$ was considered as statistical difference.

\section{Results}

\section{Study population}

A total of 32 patients were enrolled and all were completed with a 12 months follow-up. Each group was 16 patients, 11 were male and 5 were female. The age was $47.75 \pm 15.28$ in RBI group and $39.75 \pm 15.08$ in control group. The fracture type in each group was: 11 patients were $42 \mathrm{~A} 1,1$ patient was $42 \mathrm{~A} 2$, 3 patients were $42 \mathrm{~B} 2$ and 1 patient was $42 \mathrm{C} 2$. The baselines of participants were in Table 1 (the detail of each patient was in supplementary materials). There was no significant difference in baseline data between the two groups, and the two groups were comparable.
Table 1 The baselines of participants

\begin{tabular}{|c|c|c|c|}
\hline & $\begin{array}{l}\text { RBI therapy } \\
\text { group } \\
(n=16)\end{array}$ & $\begin{array}{l}\text { Control group } \\
(n=16)\end{array}$ & $P$ value \\
\hline Age(y) & $47.75 \pm 15.28$ & $39.75 \pm 15.08$ & 0.147 \\
\hline \multicolumn{4}{|l|}{ Sex } \\
\hline Female & 5 & 5 & $<0.99$ \\
\hline Male & 11 & 11 & $<0.99$ \\
\hline $\mathrm{BMI}(\mathrm{kg} / \mathrm{m} 2)$ & $23.25 \pm 2.80$ & $26.01 \pm 5.22$ & 0.073 \\
\hline \multicolumn{4}{|l|}{ Affected side } \\
\hline Left & 8 & 10 & 0.722 \\
\hline Right & 8 & 6 & 0.722 \\
\hline \multicolumn{4}{|l|}{ Fracture type } \\
\hline $42 \mathrm{~A} 1$ & 11 & 11 & $<0.99$ \\
\hline $42 \mathrm{~A} 2$ & 1 & 1 & $<0.99$ \\
\hline $42 B 2$ & 3 & 3 & $<0.99$ \\
\hline $42 \mathrm{C} 2$ & 1 & 1 & $<0.99$ \\
\hline \multicolumn{4}{|l|}{ Injury reason } \\
\hline Falling by self & 13 & 9 & 0.252 \\
\hline Traffic accident & 3 & 7 & 0.252 \\
\hline $\begin{array}{l}\text { Timing between } \\
\text { trauma and surgical } \\
\text { treatment }(\mathrm{d})^{\mathrm{a}}\end{array}$ & $4.0(6.0-2.0)$ & $5.0(3.5)$ & 0.761 \\
\hline \multicolumn{4}{|l|}{ Combination diseases } \\
\hline Hypertension & 6 & 2 & 0.22 \\
\hline Diabetes mellitus & 3 & 0 & 0.226 \\
\hline $\begin{array}{l}\text { Coronary heart } \\
\text { disease }\end{array}$ & 2 & 0 & 0.484 \\
\hline Cerebral infarction & 0 & 0 & $<0.99$ \\
\hline Allergic history & 3 & 1 & 0.6 \\
\hline Smoking history & 8 & 2 & 0.054 \\
\hline $\begin{array}{l}\text { Excessive drinking } \\
\text { history }\end{array}$ & 4 & 3 & $<0.99$ \\
\hline
\end{tabular}

${ }^{a}$ Because the data is skewed distribution, it was represented by median (quartile range) and compared by Mann-Whitney $U$ test. The enumeration data was compared by Fischer's exact test as the small size

\section{Primary outcome}

Two experienced researchers recorded the outcomes. All the fractures were healed and the bone healing time was $3(1)$ months in RBI group. However, the bone healing time of control group was 4(1) and there was statistical difference between the two groups $(p<0.01)$ (Table 2, the detail of each patient was in supplementary materials).

\section{Secondary outcomes}

There was no patient with fracture delayed union and nonunion and also no patient with venous thrombosis of lower limbs in RBI group. 2 patients were delayed union and no patient was nonunion in the control group. In RBI group, the Lysholm knee score was 83(6) at 6 months and 100(8) at 12 months. In the control 
Table 2 The outcomes of participants

\begin{tabular}{|c|c|c|c|}
\hline & $\mathrm{RBI}$ therapy group $(n=16)$ & Control group $(n=16)$ & $P$ value \\
\hline Operation time(h) & $2.29 \pm 0.74$ & $1.96 \pm 0.75$ & 0.217 \\
\hline Intraoperative blood loss (ml) ${ }^{\mathrm{a}}$ & $100(50)$ & $50(40)$ & 0.055 \\
\hline Bone healing time $(m)^{\mathrm{a}}$ & $3(1)$ & $4(1)$ & $<0.01$ \\
\hline Delayed union and nonunion(n) & 0 & 2 & 0.484 \\
\hline Venous thrombosis of lower limbs(n) & 0 & 3 & 0.226 \\
\hline \multicolumn{4}{|l|}{ Johner-Wruhs scores ${ }^{\mathrm{a}}(\%)$} \\
\hline 6 months & $100 \%$ & $87.50 \%$ & 0.484 \\
\hline 12 months & $100 \%$ & $87.50 \%$ & 0.484 \\
\hline \multicolumn{4}{|l|}{ Lysholm knee score $^{\mathrm{a}}(\mathrm{s})$} \\
\hline 6 months & $83(6)$ & $78(4)$ & $<0.01$ \\
\hline 12 months & $100(8)$ & $90.5(17)$ & 0.014 \\
\hline \multicolumn{4}{|l|}{ VAS scores ${ }^{\mathrm{a}}(\mathrm{s})$} \\
\hline Preoperative & $8(1)$ & $7.5(1)$ & $>0.99$ \\
\hline 2 weeks & $6(1)$ & $7(0.5)$ & 0.016 \\
\hline 1 month & $4(1)$ & $4(1.5)$ & 0.187 \\
\hline 2 months & $3(1.5)$ & $4(1)$ & 0.146 \\
\hline 3 months & $3(0.5)$ & $3(2)$ & 0.84 \\
\hline Postoperative complications(n) & 0 & 3 & 0.226 \\
\hline
\end{tabular}

${ }^{a}$ Because the data is skewed distribution, it was represented by median (quartile range) and compared by Mann-Whitney $U$ test. The enumeration data was compared by Fischer's exact test as the small size. Johner-Wruhs scores was shown by excellent and good rate, besides, all the postoperative complications were venous thrombosis

group, the Lysholm knee score was 78(4) at 6 months and 90.5(17) at 12 months, there was statistical difference between the two groups ( $p<0.01, p=0.014$, respectively). VAS scores were preoperative postoperative 2 weeks $6(1)$ in RBI group and 7(0.5) in the control group, there was statistical difference between the two groups $(p=0.016)$. There were 2 patients with postoperative complications, all were intramuscular venous thrombosis of lower extremity, however, there was no statistical difference between the two groups $(p=0.226)$ (Table 2 , the detail of each patient was in supplementary materials).

The serum BMP-2 were postoperative 2 weeks $224.69 \pm 15.17 \mathrm{pg} / \mathrm{ml}, 1$ month $211.93 \pm 16.79 \mathrm{pg} / \mathrm{ml}$ in RBI group and $206.86 \pm 12.49 \mathrm{pg} / \mathrm{ml}, 200.71 \pm 10.23 \mathrm{pg} /$ $\mathrm{ml}$ in the control group, there was statistical difference between the two groups $(p<0.01, p=0.031$, respectively). The serum OC were postoperative 2 weeks $25.31 \pm 0.62 \mathrm{ng} / \mathrm{ml}, 1$ month $22.97 \pm 0.55 \mathrm{ng} / \mathrm{ml}$ in RBI group and $24.61 \pm 0.33 \mathrm{ng} / \mathrm{ml}, 22.19 \pm 1.27 \mathrm{ng} / \mathrm{ml}$ in the control group, there was statistical difference between the two groups $(p<0.01, p=0.037$, respectively). The serum BS-ALP were postoperative 2 weeks $124.81 \pm 7.98 \mathrm{ng} /$ $\mathrm{ml}, 1$ month $122.60 \pm 8.53 \mathrm{ng} / \mathrm{ml}$ in RBI group and $118.91 \pm 4.52 \mathrm{pg} / \mathrm{ml}, 110.07 \pm 4.14 \mathrm{pg} / \mathrm{ml}$ in the control group, there was statistical difference between the two groups ( $p=0.017, p=<0.01$, respectively) (Table 3 , the detail of each patient was in supplementary materials) (Figs. 2 and 3).
Table 3 The serum cytokines of participants

\begin{tabular}{cccc}
\hline & $\begin{array}{l}\text { RBI therapy } \\
\text { group }(\boldsymbol{n}=\mathbf{1 6})\end{array}$ & Control group $(\boldsymbol{n}=\mathbf{1 6})$ & P value \\
\hline BMP-2(pg/ml) & & & \\
Preoperative & $191.75 \pm 13.32$ & $194.86 \pm 11.94$ & 0.492 \\
2 weeks & $224.69 \pm 15.17$ & $206.86 \pm 12.49$ & 0.001 \\
1 month & $211.93 \pm 16.79$ & $200.71 \pm 10.23$ & 0.031 \\
2 months & $185.26 \pm 15.80$ & $187.63 \pm 11.30$ & 0.63 \\
3 months & $178.15 \pm 14.10$ & $173.99 \pm 9.55$ & 0.337 \\
OC(ng/ml) & & & \\
Preoperative & $23.26 \pm 0.40$ & $23.03 \pm 0.56$ & 0.184 \\
2 weeks & $25.31 \pm 0.62$ & $24.61 \pm 0.33$ & 0.001 \\
1 month & $22.97 \pm 0.55$ & $22.19 \pm 1.27$ & 0.037 \\
2 months & $19.63 \pm 0.31$ & $19.16 \pm 0.92$ & 0.07 \\
3 months & $17.28 \pm 0.41$ & $16.95 \pm 0.60$ & 0.086 \\
BS-ALP(ng/ml) & & & \\
Preoperative & $104.47 \pm 9.03$ & $110.40 \pm 8.34$ & 0.063 \\
2 weeks & $124.81 \pm 7.98$ & $118.91 \pm 4.52$ & 0.017 \\
1 month & $122.60 \pm 8.53$ & $110.07 \pm 4.14$ & 0.001 \\
2 months & $105.94 \pm 5.86$ & $102.06 \pm 5.95$ & 0.073 \\
3 months & $99.18 \pm 5.64$ & $98.63 \pm 6.07$ & \\
\hline
\end{tabular}




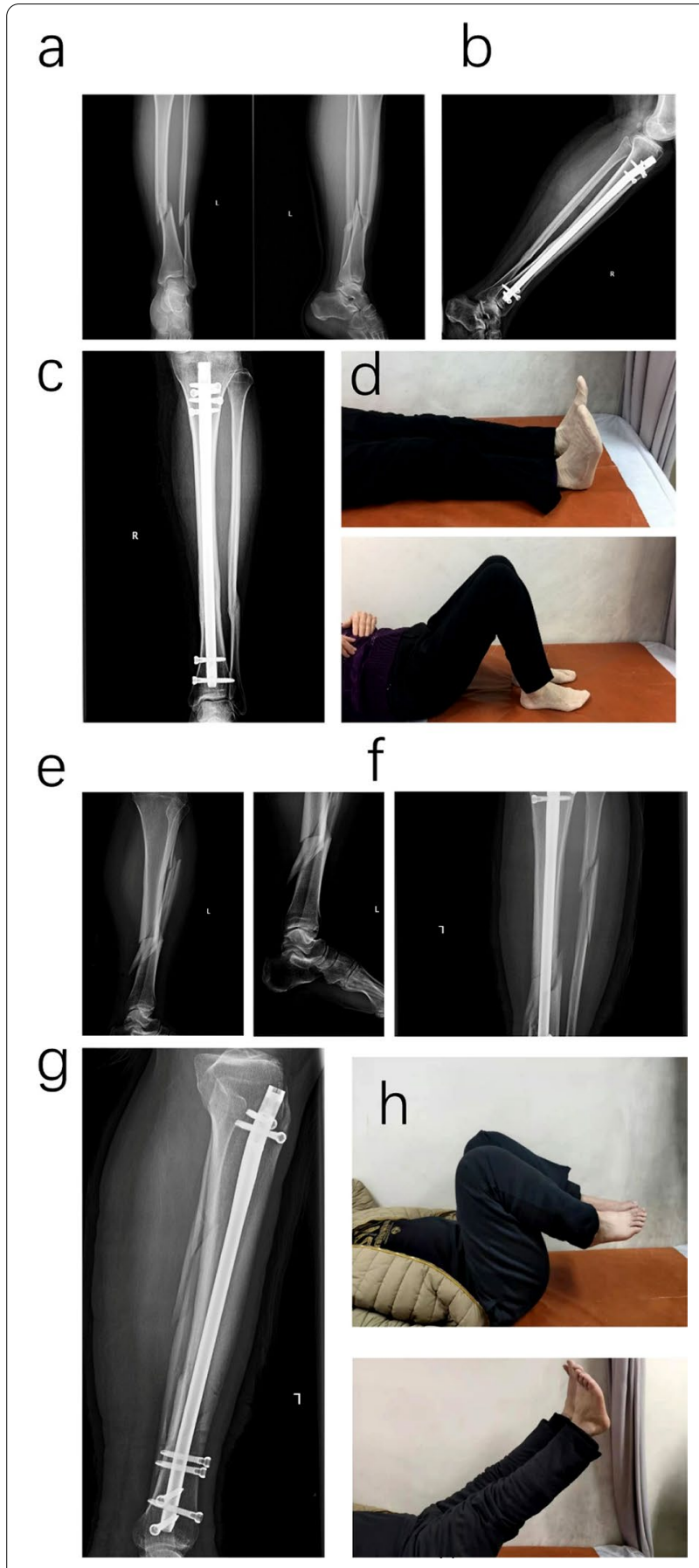

Fig. 2 X-rays and functional activity of the RBI group. a-d Series number 14 patients. a Preoperative $X$-rays showed tibia shaft fracture and fracture type was $42 \mathrm{~A} 1 ; \mathbf{b}$ and $\mathbf{c} X$-rays of postoperative 3 months showed bone healed. $\mathbf{d}$ the limb activity picture showed the satisfied limb motion. e- $\mathbf{h}$ Series number 1 patients. e Preoperative $X$-rays showed tibia shaft fracture and fracture type was $42 C 2 ; \mathbf{f}-\mathbf{h}$ X-rays of postoperative 2 months showed that fracture was not healed but the limb motion was satisfied

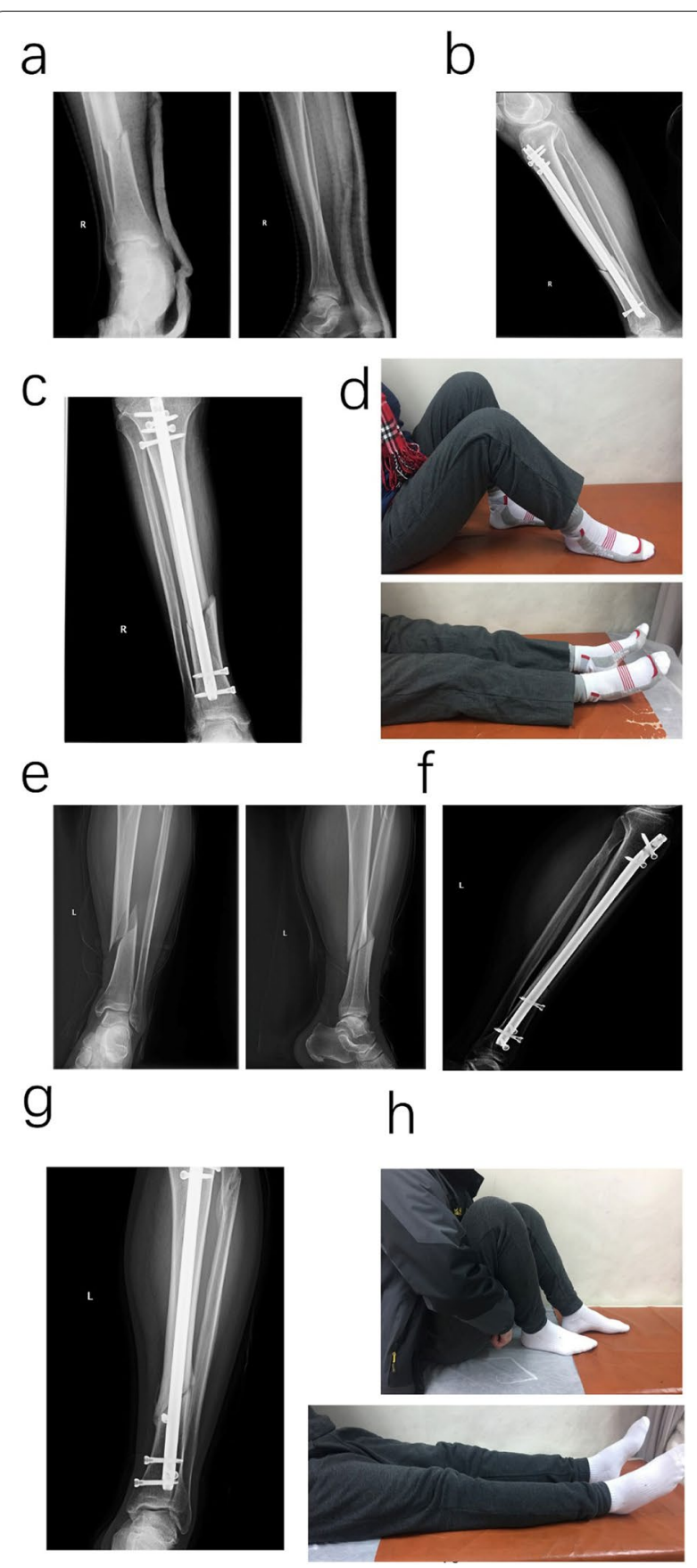

Fig. $3 X$-rays and functional activity of the control group. a-d Series number 2 patients. a Preoperative $X$-rays showed fracture type was $42 \mathrm{~A} 1 ; \boldsymbol{b}$ and $\mathbf{c} X$-rays of postoperative 2 months showed no obvious callus formation. $\mathbf{d}$ The limb activity picture showed the limb motion. e-h Series number 4 patients. e Preoperative $X$-rays showed fracture type was $42 \mathrm{~A} 1 ; \mathbf{f}-\mathbf{h} \mathbf{X}$-rays of postoperative 3 months showed that the fracture line could still be seen although the callus formed, besides, the limb motion was not recovery 


\section{Discussion}

Tibia shaft fracture is a common fracture type in clinic and has a $24 \%$ incidence rate in work-age adults [1-3, 16]. The nonunion rate of tibia shaft fracture is about $14 \%$ that is much higher than the average nonunion rate of long-bone fracture [1-3]. As for reducing disruption of local blood supply, intramedullary nails have been wildly used in clinic at present [17-19]. Despite strict adherence to the guidelines, the healing time and nonunion rate of tibial shaft fractures are not decreased significantly [1-3].

This study was to explore a method to promote bone healing. RBI was a method to accelerate endogenous promoting mechanism. The previous animal studies showed that RBI could obviously promote bone healing [4, 5]. We established a rat tibia shaft fracture model and used $0.8 \mathrm{~mm} \mathrm{~K}$-wire as an intermedullary fixator. IPC of rats was used to make affected side or health side limb RBI. We found that RBI accelerated bone healing both doing on the affected side and health side limb. Besides, RBI increased the expression of serum and bone fracture site BMP-2, vascular endothelial growth factor (VEGF), ALP and transforming growth factor- $\beta 1$ (TGF- $\beta 1$ ). RBI on the health side inhibited the secretion of interleukin 6 (IL6) and promoted the secretion of interleukin 10 (IL-10). However, RBI on the affected side limb decreased the level of IL-10 and accelerated the IL-6 synthesis [5].

Based on the animal experiment finding, we tried to use RBI on tibia shaft fracture patients. The study is a prospective clinical trial and has the strict inclusion criteria. We enrolled patients aged from 18 to 65 years and with fresh, closed fracture, which excluded the influences of children, open fractures and old fractures. The participants were received a similar surgical operation and we excluded the patients received plate fixation. Meanwhile, the operation was carried out by the same team. By these limitations, the impacts of operation on outcome were minimized. RBI made the limb about $30 \mathrm{~s}$ ischemia and cause a change of blood flow in patients, so we excluded the patients with vascular diseases, especial those with venous thrombosis. Immune diseases and long-term glucocorticoid therapy have an impact on fracture healing, so patients with these disease or drug history were excluded.

Finally, 32 patients were enrolled and each group was 16 patients. The age was $47.75 \pm 15.28$ and 13 was fallen by themselves in RBI group, besides, the age was $47.75 \pm 15.28$ and 9 was fallen by themselves in the control group which meant that most patients were the low energy injuries. After 4 weeks RBI, we found that the bone healing time was 3(1) months that was much shorter than previous literature reported and the control group [1-3]. In additions, there was no patient with fracture delayed union and nonunion. RBI might reduce the nonunion incidence [1-3]. The excellentgood rate of Johner-Wruhs scores was $100 \%$ that meant the limb function recovered satisfactorily. Besides, RBI decreased the VAS scores compared with previous studies and the control group at postoperative 2 weeks [17-20]. There was no venous thrombosis of lower limbs and postoperative complication occurred in any of the patients in RBI group so we thought that RBI might be safety to patients, however, this conclusion was needed many large sample-size randomized controlled trials to prove.

The limitations of this study were too many. First, the sample size of this trial was too small and clinical studies with large sample size are needed as this study was only an exploratory trial. Second, we were unable to accurately assess the effects of RBI on fracture healing as the small sample size. Thirdly, the included patients had a wide age range, both high-trauma and lowtrauma injuries, so it is necessary to expand the sample size for subgrouping analysis. Finally, we did not make the blinding so there may be selection bias.

\section{Conclusions}

RBI is a new method to accelerate bone healing in tibia shaft fracture patients and is a simple and noninvasive method. It can be widely used, especially in poor countries or economically underdeveloped areas.

\section{Abbreviations}

RBI: Repetitive brief ischemia; IGF-2: Insulin-like growth factor-2; BMP-2: Bone morphogenetic protein-2; VEGF: Vascular endothelial growth factor; TGF- $\beta$ : Transforming growth factor- $\beta$; ALP: Alkaline phosphatase; OC: Osteocalcin; BSALP: Bone specific alkaline phosphatase; BMI: Body mass index; IPC: Intermittent pneumatic compression; VAS: Visual analogue scale; ELISA: Enzyme-linked immuno sorbent assay.

\section{Supplementary Information}

The online version contains supplementary material available at https://doi. org/10.1186/s12891-021-04515-y.

Additional file 1.

\section{Acknowledgements}

We thank that Zosing company sold the IPC service and Cusabio company sold the ELISA kit.

\section{Statement}

We confirmed that all methods were carried out in accordance with relevant guidelines and regulations.

\section{Authors' contributions}

$J L Z$ designed the trials. YL and DW enrolled the patients and recorded the baseline of participants. WRL and WL did the RBI treatment. DW and XBZ recorded the outcomes. WRL tested the serum cytokines. YD collected the data and DW analyzed the data. DW wrote the manuscript JLZ revised the manuscript. The author(s) read and approved the final manuscript. 


\section{Funding}

This work is Supported by Beijing Natural Science Foundation (7202049) which was obtained by Junlin Zhou. The role of the funding was in trials and data collection.

\section{Availability of data and materials}

The supplemental data used to support the findings of this study have been submitted in the supplementary materials.

\section{Declarations}

\section{Ethics approval and consent to participate}

This study was approved by the ethics committee of Beijing Chao-Yang Hospital Affiliated to Capital Medical University (2017-5-8-2). All the participants were signed the informed consent for this clinical research.

\section{Consent for publication}

Not applicable.

\section{Competing interests}

The authors have no conflict of interest or financial disclosures.

\section{Author details}

${ }^{1}$ Department of Orthopedics, Beijing Chaoyang Hospital, Capital Medical University, 8 Gongren Tiyuchang Nanlu, Chaoyang District, Beijing 100020, China. ${ }^{2}$ Department of Respiratory and Critical Care Medicine, Beijing Chaoyang Hospital, Capital Medical University, 8 Gongren Tiyuchang Nanlu, Chaoyang District, Beijing 100020, China. ${ }^{3}$ Beijing Tongzhou Xinhua Hospital, Beijing 101100, China. ${ }^{4}$ Third Department of Traumatology, The Third Hospital of Shijiazhuang, Shijiazhuang 050000, China.

Received: 20 March 2021 Accepted: 8 July 2021

Published online: 20 July 2021

\section{References}

1. Ekegren $C L$, Edwards ER, de Steiger R, Gabbe BJ. Incidence, costs and predictors of non-union, delayed union and mal-union following long bone fracture. Int J Environ Res Public Health. 2018;15(12):2845.

2. Zura R, Xiong Z, Einhorn T, Watson JT, Ostrum RF, Prayson MJ, et al. Epidemiology of fracture nonunion in 18 human bones. JAMA Surg. 2016;151(11):e162775.

3. Bell A, Templeman D, Weinlein JC. Nonunion of the femur and tibia: an update. Orthop Clin North Am. 2016;47(2):365-75.

4. Liu Y, Wang D, Zhao Y, Zhou J. Repetitive brief ischemia can promote bone healing in a rat tibia fracture model. Int J Clin Exp Med. 2016;9(11):20960-7.

5. Liu Y, Wang D, Wu X, Zhou J. Ischemia injury: a new method accelerates bone healing in a rat tibia fracture model. Biomed Res Int. 2019;2019:6592464.

6. Lu Y, Wang B, Hu B, Ren C, Sun L, Li M, et al. Tibial shaft fractures treated with intramedullary nailing and reduction device assistance. Int Orthop. 2020;44(11):2413-20.
7. Qian C, Huhtakangas J, Juvela S, Bode MK, TatlisumakT, Savolainen $M$, et al. Early vs. late enoxaparin for the prevention of venous thromboembolism in patients with ICH: a double blind placebo controlled multicenter study. Clin Neurol Neurosurg. 2021;202:106534.

8. Atan T, Bahar-Özdemir Y. The effects of complete decongestive therapy or intermittent pneumatic compression therapy or exercise only in the treatment of severe lipedema: a randomized controlled trial. Lymphat Res Biol. 2020;19(1):86-95.

9. Lobastov K, Sautina E, Alencheva E, Bargandzhiya A, Schastlivtsev I, Barinov $V$, et al. Intermittent pneumatic compression in addition to standard prophylaxis of postoperative venous thromboembolism in extremely high-risk patients (IPC SUPER). Ann Surg. 2020;274(1):63-69.

10. Sharma B, Kumar Shakunt R, Patel J, Pal CP. Outcome of limb reconstruction system in tibial infected non-union and open tibial diaphysial fracture with bone loss. J Clin Orthop Trauma. 2020;15:136-8.

11. Arazi M, Canbora MK. Fracture healing. In: Musculoskeletal research and basic science. 2016.

12. Zhang S, Wu X, Liu L, Wang C. Removal of interlocking intramedullary nail for relieve of knee pain after tibial fracture repair: a prospective study. J Orthop Surg. 2017;25(1):2309499016684748.

13. Nagaraj R, Shivanna S. Pattern of multiligament knee injuries and their outcomes in a single stage reconstruction: experience at a tertiary orthopedic care centre. J Clin Orthop Trauma. 2020;15:156-60.

14. Vicenti G, Bizzoca D, Cotugno D, Carrozzo M, Riefoli F, Rifino F, et al. The use of a gentamicin-coated titanium nail, combined with RIA system, in the management of non-unions of open tibial fractures: a single centre prospective study. Injury. 2020;51(Suppl 3):S86-91.

15. Corey RM, Park NK, Cannada LK. Segmental tibia fractures: an analysis of complication and healing rates. J Orthop Trauma. 2018;32(6):296-300.

16. Nam D, Balasuberamaniam P, Milner K, Kunz M, Vachhani K, Kiss A, et al. Lithium for Fracture Treatment (LiFT): a double-blind randomised control trial protocol. BMJ Open. 2020;10(1):e031545.

17. Kang H, Rho JY, Song JK, Choi J, Kwon YS, et al. Comparison between intramedullary nailing and minimally invasive plate osteosynthesis for tibial shaft fractures. Injury. 2021;52(4):1011-6.

18. Kati YA, Öken OF, Yıldırım AO, Köse O, Ünal M. May minimally invasive plate osteosynthesis be an alternative to intramedullary nailing in selected spiral oblique and spiral wedge tibial shaft fractures? Jt Dis Relat Surg. 2020;31(3):494.

19. Song X, Huang X, Yakufu M, Yan B, Feng C. Minimally invasive plate osteosynthesis or conventional intramedullary nailing for distal tibial fractures: a cohort study protocol. Medicine (Baltimore). 2020;99(33):e21779.

20. Maharjan R, Shrestha BP, Chaudhary P, Rijal R, Shah Kalawar RP. Functional outcome of patients of tibial fracture treated with solid nail (SIGN nail) versus conventional hollow nail - a randomized trial. J Clin Orthop Trauma. 2021;12(1):148-60.

\section{Publisher's Note}

Springer Nature remains neutral with regard to jurisdictional claims in published maps and institutional affiliations.
Ready to submit your research? Choose BMC and benefit from:

- fast, convenient online submission

- thorough peer review by experienced researchers in your field

- rapid publication on acceptance

- support for research data, including large and complex data types

- gold Open Access which fosters wider collaboration and increased citations

- maximum visibility for your research: over 100M website views per year

At BMC, research is always in progress.

Learn more biomedcentral.com/submissions 